\title{
Density and Hardness Gradients of Functionally Graded Material Ring Fabricated from Al-3 mass\% Cu Alloy by a Centrifugal In-Situ Method
}

\author{
Yoshimi Watanabe ${ }^{1,2}$, Hisashi Sato ${ }^{1,3}$, Tetsuro Ogawa ${ }^{4}$ and Ick-Soo Kim ${ }^{4}$ \\ ${ }^{1}$ Omohi College, Nagoya Institute of Technology, Nagoya 466-8555, Japan \\ ${ }^{2}$ Department of Engineering Physics, Electronics and Mechanics Graduate School of Engineering, \\ Nagoya Institute of Technology, Nagoya 466-8555, Japan \\ ${ }^{3}$ Department of Techno-Business Administration Graduate School of Engineering, \\ Nagoya Institute of Technology, Nagoya 466-8555, Japan \\ ${ }^{4}$ Department of Functional Machinery and Mechanics Shinshu University, Ueda 386-8567, Japan
}

In present study, the $\mathrm{Al}-\mathrm{Al}_{2} \mathrm{Cu}$ functionally graded material (FGM) ring was fabricated from $\mathrm{Al}-3$ mass\% $\mathrm{Cu}$ initial master alloy by the centrifugal in-situ method. In the case of Al-3 mass \% Cu alloy, the density of the primary $\alpha$-Al crystal is larger than that of the molten $\mathrm{Al}$ alloy. Therefore, the solid $\alpha$-Al phase migrates towards the outer periphery of the ring when the centrifugal force is applied in the early stage of solidification. Consequently, since the $\mathrm{Cu}$ concentration within the FGM ring monolithically increases towards the ring's inner position, the FGM ring, whose density increases toward inner region, can be successfully fabricated by the centrifugal in-situ method from dilute Al-Cu alloy. It is also found that the hardness increases towards the inner region of the ring within the $\mathrm{Al}^{-\mathrm{Al}}{ }_{2} \mathrm{Cu}$ FGM ring. The hardness of the fabricated specimens at the inner region of the ring increases in a large scale by the heat treatments, since Guinier-Preston (GP) zones would be formed by aging. [doi:10.2320/matertrans.MB200710]

(Received February 27, 2007; Accepted August 6, 2007; Published September 12, 2007)

Keywords: functionally graded material (FGM), density, solidification, viscosity, aluminum-copper alloy, $\mathrm{Al}_{2} \mathrm{Cu}$

\section{Introduction}

A functionally graded material (FGM) is usually a combination of two materials that has a compositional gradient from one material at one surface to another material at the opposite surface. This compositional gradient allows the creation of multiple properties without any mechanically weak interface. It is possible with these materials to obtain a combination of properties that cannot be achieved in conventional materials. This makes FGMs preferable in many applications. ${ }^{1,2)}$

A variety of methods have been explored in attempts to fabricate the FGMs, ${ }^{1,2)}$ and one of them is centrifugal solidparticle method. ${ }^{3-6)}$ In this method, a thick walled FGM ring can be fabricated from a mixture of molten metal and solid particles. The composition gradient is formed mainly from the difference in the centrifugal force produced by the difference in density between the molten metal and solid particles. The moving direction of the solid particles in the molten matrix is determined by the density difference between the molten metal and particles. If the density of solid particles is higher than that of molten matrix, the particles migrate toward outer region of the FGM ring during the centrifugal solid-particle method, and vice versa. For example, $\mathrm{SiC}^{5)}$ and Shirasu (volcanic eruptions, main composition: $\mathrm{SiO}_{2}$ and $\left.\mathrm{Al}_{2} \mathrm{O}_{3}\right)^{7)}$ dispersed in $\mathrm{Al}$ matrix FGM rings have been fabricated by the centrifugal solidparticle method. During the processing of the centrifugal solid-particle method, $\mathrm{SiC}$ (density: $3.15 \mathrm{Mg} / \mathrm{m}^{3}$ ) and Shirasu (density: $2 \mathrm{Mg} / \mathrm{m}^{3}$ ) particles in molten $\mathrm{Al}$ (density at $700^{\circ} \mathrm{C}: 2.37 \mathrm{Mg} / \mathrm{m}^{3}$ ) migrate toward the outer and the inner periphery of the FGM ring, respectively.

In the case of Al-SiC FGM ring fabricated by the centrifugal solid-particle method, since the volume fraction of $\mathrm{SiC}$ particles with higher density than $\mathrm{Al}$ matrix increases toward the outer region of the ring, the overall density of the FGM ring also increases toward this direction. On the other hand, the volume fraction of Shirasu particles, which density is smaller than that of $\mathrm{Al}$, increases in the inner region of the ring, and then the overall density of the Al-Shirasu FGM ring increases toward the outer region of the ring. In this way, the density of the outer part of the FGM rings is larger than that of the inner part of the ring in nature. In our resent study, theoretical study on fabrication of FGM with density gradient by a centrifugal solid-particle method has been carried out. ${ }^{8)}$ The graded distributions of the two kinds of solid spherical particles under applied centrifugal force are analyzed theoretically. It is shown that the FGM ring in which the density will increase toward interior region from the outer region can be fabricated by the centrifugal solid-particle method using a combination of large diameter particles with low density and small one with high density. ${ }^{8)}$

Meanwhile, there is another FGM ring fabrication method using the centrifugal force, namely a centrifugal in-situ method, by which the centrifugal force can be applied during the solidification to both the primary crystal and the matrix. ${ }^{9-11)}$ This situation can be realized when the processing temperature is higher than the liquidus of the reinforcement materials in phase diagram. Usually, the density of the outer part of the FGM rings fabricated by the centrifugal insitu method is larger than that of the inner part of the ring.

In many cases, the volume fraction of reinforcement particles increases towards the outer region of Al-based FGM rings, since the density of reinforcement particles is usually higher than that of the molten $\mathrm{Al}$. Consequently, the hardness and wear resistance of $\mathrm{Al}$ based FGM ring fabricated by the centrifugal method increase towards the ring's outer region. ${ }^{12,13)}$ When the inner region of the ring is required to 
have high mechanical properties, the density of reinforcement particles should have a smaller value compared to that of the molten Al. However, the above systems are limited, and the mechanical properties of the lighter particlereinforced FGM would not be strong. Therefore, a new approach is needed to fabricate an FGM ring, in which both density and mechanical property gradients increase towards the ring's inner region.

It is reported that the volume change accompanying the solidification of pure $\mathrm{Al}$ is $7.14 \% .{ }^{14)}$ In the case of dilute $\mathrm{Al}$ alloys, the density of the primary $\alpha$-Al crystal is larger than that of the molten $\mathrm{Al}$ alloy. If this system is used for the initial master alloy of the centrifugal in-situ method, the primary $\alpha$ Al crystal particles should migrate towards the outer periphery of the ring. Then, an FGM ring, whose density would increase toward the inner region of the ring, can be fabricated by using this phenomenon.

To address this issue, we have used an $\mathrm{Al}-3$ mass $\% \mathrm{Cu}$ alloy as an initial material for the centrifugal in-situ method. As it will be described in the next section, since the density of the primary $\alpha$ - $\mathrm{Al}$ crystal is larger than that of a molten Al3 mass $\% \mathrm{Cu}$ alloy at early stage of solidification, primary $\alpha$ $\mathrm{Al}$ solid particles migrate towards the outer periphery of the ring. The volume fraction of the precipitates of $\mathrm{Al}_{2} \mathrm{Cu}$ intermetallic compound, which has higher density than $\alpha$-Al phase, would increase towards the inner periphery of the ring. Then the density of the FGM ring should increase toward the ring inner region.

\section{Density Change During Solidification of Al-3 mass\%- Cu Alloy}

The density difference between the primary crystal and retained molten alloy is one of the most important physical properties to understand the formation mechanism of graded microstructure within the FGM fabricated under the centrifugal force. In this section, we will describe first the density change during the solidification of the $\mathrm{Al}-3$ mass $\% \mathrm{Cu}$ alloy. Figure 1 shows the density of molten Al-Cu alloys at $600^{\circ} \mathrm{C}$, $700^{\circ} \mathrm{C}, 800^{\circ} \mathrm{C}$ and $900^{\circ} \mathrm{C}$, as well as that of a solid $\mathrm{Al}-\mathrm{Cu}$ alloy at $20^{\circ} \mathrm{C}^{15)}$ Dotted line in $600^{\circ} \mathrm{C}$ is an extrapolated line. It can be seen, the density of molten $\mathrm{Al}-\mathrm{Cu}$ alloys increases with increasing the $\mathrm{Cu}$ concentration, and the density as a function of $\mathrm{Cu}$ concentration has a positive curvature.

Figure 2 presents the $\mathrm{Al}-\mathrm{Cu}$ phase diagram. ${ }^{16)}$ When the $\mathrm{Al}-3$ mass $\% \mathrm{Cu}$ alloy is cooled from a temperature within the liquid-phase region, the solid $\alpha$-Al phase begins to form at about $653^{\circ} \mathrm{C}$ and the chemical composition of primary $\alpha-\mathrm{Al}$ phase is 0.5 mass $\% \mathrm{Cu}$ in equilibrium. With continued cooling, the compositions of the liquid and $\alpha$-Al phases follow the liquidus and solidus lines, respectively. For example, they are about 8.0 mass $\% \mathrm{Cu}$ and $1.1 \mathrm{mass} \% \mathrm{Cu}$ at $640^{\circ} \mathrm{C}$ and are about 14.4 mass $\% \mathrm{Cu}$ and 2.1 mass $\% \mathrm{Cu}$ at $620^{\circ} \mathrm{C}$, respectively. The solidification process is complete at about $600^{\circ} \mathrm{C}$. At just the above this temperature, the composition of the last remaining liquid $\mathrm{Al}-\mathrm{Cu}$ alloy is about 20.0 mass $\% \mathrm{Cu}$, while that of the $\alpha-\mathrm{Al}$ phase is approximately 3 mass $\% \mathrm{Cu}$.

Meanwhile, the density of a solid Al-Cu alloy at elevated temperature can be calculated by density and linear thermal expansion coefficient using eq. (1),

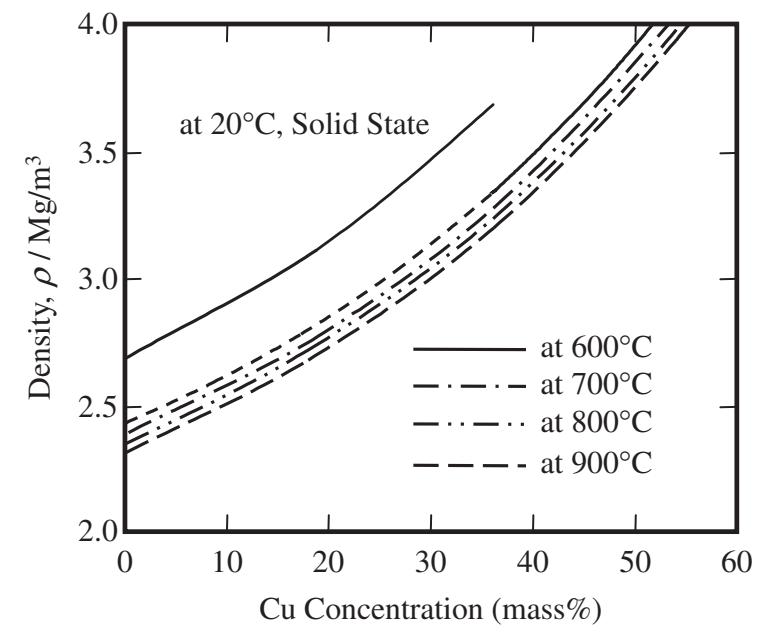

Fig. 1 Density of molten Al-Cu alloys at $600^{\circ} \mathrm{C}, 700^{\circ} \mathrm{C}, 800^{\circ} \mathrm{C}$ and $900^{\circ} \mathrm{C}$, as well as that of a solid $\mathrm{Al}-\mathrm{Cu}$ alloys at $20^{\circ} \mathrm{C}$, after Bornemann and Sauerwald. ${ }^{15)}$

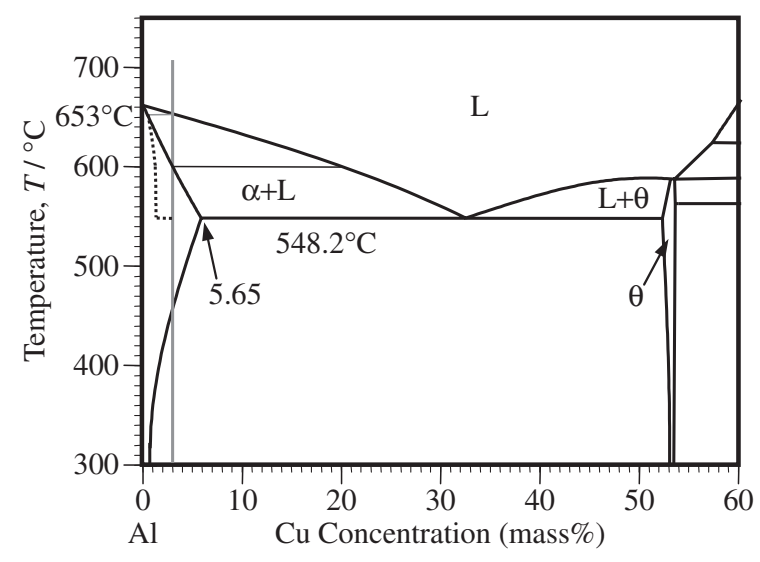

Fig. 2 The Al-Cu phase diagram. ${ }^{16)}$

$$
\rho_{T}=\frac{\rho_{0}}{(1+\alpha \Delta T)^{3}}
$$

where $\rho_{T}, \alpha, \Delta T$ and $\rho_{o}$ are density at temperature $T$, linear thermal expansion coefficient, temperature change and density at base temperature, respectively. It is known that the thermal expansion coefficient of pure $\mathrm{Al}$ at $27^{\circ} \mathrm{C}$, $327^{\circ} \mathrm{C}$ and $527^{\circ} \mathrm{C}$ is $23.2 \times 10^{-6} \mathrm{~K}^{-1}, 28.4 \times 10^{-6} \mathrm{~K}^{-1}$ and $34.0 \times 10^{-6} \mathrm{~K}^{-1}$, respectively. ${ }^{17)}$ Using these values, the density of solid $\alpha-\mathrm{Al}$ in $\mathrm{Al}-\mathrm{Cu}$ system at elevated temperature can be evaluated. During infinitely slow (equilibrium) solidification, the density change for liquid and solid phases during the cooling of molten $\mathrm{Al}-3$ mass\% $\mathrm{Cu}$ alloy is shown in Fig. 3.

In case of centrifugal casting, however, solidification without diffusion may take place in the solid but the liquid composition is always kept homogeneous during solidification due to an efficient stirring. The composition of the liquid, $C_{L}$, during solidification is given by the Scheil equation,

$$
C_{L}=C_{0}\left(1-f_{s}\right)^{k-1}
$$

where $C_{0}, k$ and $f_{s}$ are the initial composition, the equilibrium distribution coefficient and the mass friction of solid, respectively. ${ }^{18)}$ Assuming $C_{0}=3.0$ and $k=0.17$, the solid- 


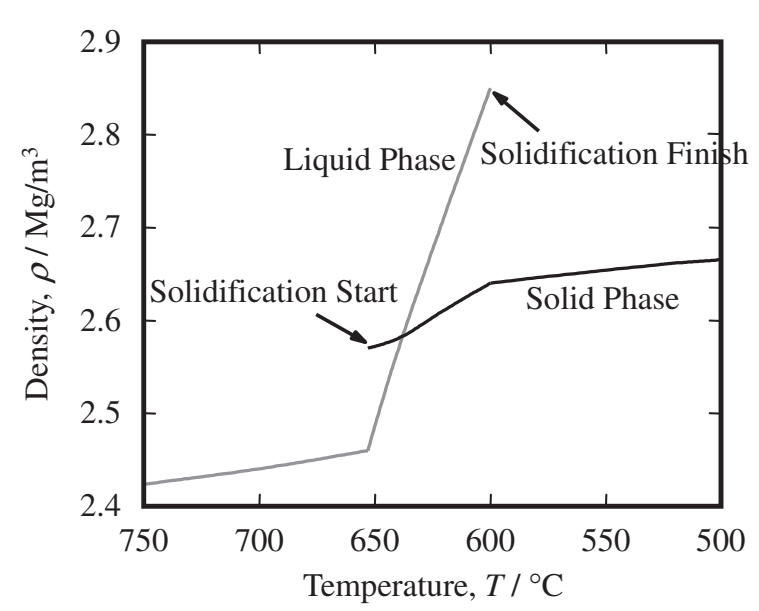

Fig. 3 Temperature dependence of densities for liquid and solid phases during the infinitely slow (equilibrium) solidification of molten Al3 mass $\% \mathrm{Cu}$ alloy.

ification process is not complete at $600^{\circ} \mathrm{C}$, at which the composition of the liquid phase becomes 20 mass $\% \mathrm{Cu}$, and the fraction of liquid phase is about $10 \%$. Even at a eutectic temperature, $5.5 \%$ liquid phase with the eutectic composition will be retained. The retained liquid phase may transform into the solid phases by the eutectic reaction at this temperature. The mean composition of the solid $\bar{C}$ s will be purer than that of the equilibrium solidus line, when there is no diffusion in the solid. When $f_{\mathrm{s}}$ calculated from $C_{\mathrm{L}}$ is $V_{\mathrm{s}}, \bar{C} \mathrm{~s}$ at $C_{\mathrm{L}}$ can be calculated by the integration of Scheil equation from 0 to $V_{\mathrm{s}}$ and the division with $V_{\mathrm{s}}$,

$$
\begin{aligned}
\overline{C \mathrm{~s}} & =\frac{1}{V_{\mathrm{s}}} \int_{0}^{\mathrm{V}_{s}} k C_{0}\left(1-f_{\mathrm{s}}\right)^{k-1} d f_{\mathrm{s}} \\
& =\frac{C_{0}}{V_{\mathrm{s}}}\left\{1-\left(1-V_{\mathrm{s}}\right)^{k}\right\} .
\end{aligned}
$$

In this study, $V_{\mathrm{s}}$ for each $C_{\mathrm{L}}$ are calculated by eq. (2) and liquidus line in equilibrium state. Then non-equilibrium solidus line $(\bar{C} s)$ are evaluated by eq. (3) and $V_{\mathrm{s}}$ calculated from eq. (2). The obtained result is shown in Fig. 2 by a dotted line.

For solidification without diffusion in the solid but with perfect mixing in the liquid, the density change for liquid and solid phases can be also calculated. Figure 4 shows the result for $\mathrm{Al}-3$ mass $\% \mathrm{Cu}$ alloy. It can be seen that the density of the liquid phase slightly increases with decreasing the temperature before the solid $\alpha$-Al phase begins to form at about $653^{\circ} \mathrm{C}$, since the chemical composition of liquid phase maintains constant (i.e., 3 mass $\% \mathrm{Cu}$ ). On the other hand, the density of liquid phase increased rapidly below $653^{\circ} \mathrm{C}$. This is because the composition of the liquid phase follows the liquidus line, as shown in Fig. 2. Temperature dependence of density for solid phase during the solidification is relatively small comparing with liquid phase, since the composition change during the solidification is small (from 0.5 mass $\% \mathrm{Cu}$ to $1.3 \mathrm{mass} \% \mathrm{Cu}$ ). It must be noted that the density of the primary $\alpha$-Al crystal with 0.5 mass $\% \mathrm{Cu}$ is larger than that of a molten Al-3 mass \% Cu alloy at $653^{\circ} \mathrm{C}$. Therefore, in the early stage of solidification, solid $\alpha$-Al phase migrates

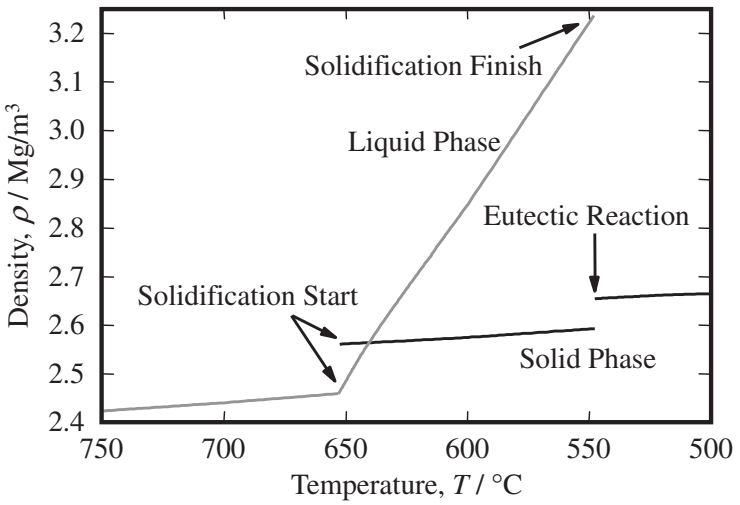

Fig. 4 Temperature dependence of densities for liquid and solid phases during the cooling of molten Al-3 mass\% Cu alloy. Solidification without diffusion may take place in the solid but the liquid composition is always kept homogeneous during solidification due to an efficient stirring.

towards the outer periphery of the ring when the centrifugal force is applied. The volume fraction of the $\mathrm{Al}_{2} \mathrm{Cu}$ intermetallic compounds would increase towards the inner periphery of the ring. Consequently, the density and hardness will increase toward inner region of the ring, since the density and hardness of the $\mathrm{Al}_{2} \mathrm{Cu}$ intermetallic compounds are larger than those of the $\alpha$-Al.

\section{Experimental Procedures}

$\mathrm{Al}-\mathrm{Al}_{2} \mathrm{Cu}$ FGM ring was fabricated by the centrifugal insitu method from $\mathrm{Al}-3$ mass $\% \mathrm{Cu}$ initial master alloy. The alloy was melted in an argon gas atmosphere at $800^{\circ} \mathrm{C}$. Only liquid phase exists in $\mathrm{Al}-3$ mass $\% \mathrm{Cu}$ alloy at $800^{\circ} \mathrm{C}$. The molten alloy was directly poured into a rotating mold, which was heated to $750^{\circ} \mathrm{C}$. The applied $G$ number was 120 , where the $G$ number is the centrifugal force in units of gravity. 3,4$)$ The ratio of the centrifugal force to the gravity $(g)$ is given by the following equation:

$$
G=\frac{F}{g}=\frac{2 \pi D N^{2}}{g}
$$

where $F(\mathrm{~N}), D(\mathrm{~m})$ and $N\left(\mathrm{~s}^{-1}\right)$ are a centrifugal force, a diameter of the cast ring and the velocity of the mold rotation, respectively. After casting, the mold was cooled in air. The fabricated ring had the outer diameter of $90 \mathrm{~mm}$, the thickness of about $20 \mathrm{~mm}$ and the length of $30 \mathrm{~mm}$.

Specimens for scanning electron microscopy (SEM) were cut from the cast ring and prepared by grinding and polishing. The specimens were examined in a Hitachi 3000 SEM equipped with electron-dispersive X-ray spectroscope (EDX). Density distribution of fabricated FGM ring was evaluated by means of Archimedes type density test at different positions. The fabricated specimen was divided into five parts of equal width along the centrifugal force direction, and density of each sample was measured. Brinell hardness test and micro Vickers hardness test were carried out to study the gradient of the mechanical property. In the present study, load and pressing for Brinell hardness test were $4900 \mathrm{~N}$ and $30 \mathrm{sec}$, respectively, whereas those for the micro Vickers hardness test were $1.96 \mathrm{~N}$ and $15 \mathrm{sec}$, respectively. 

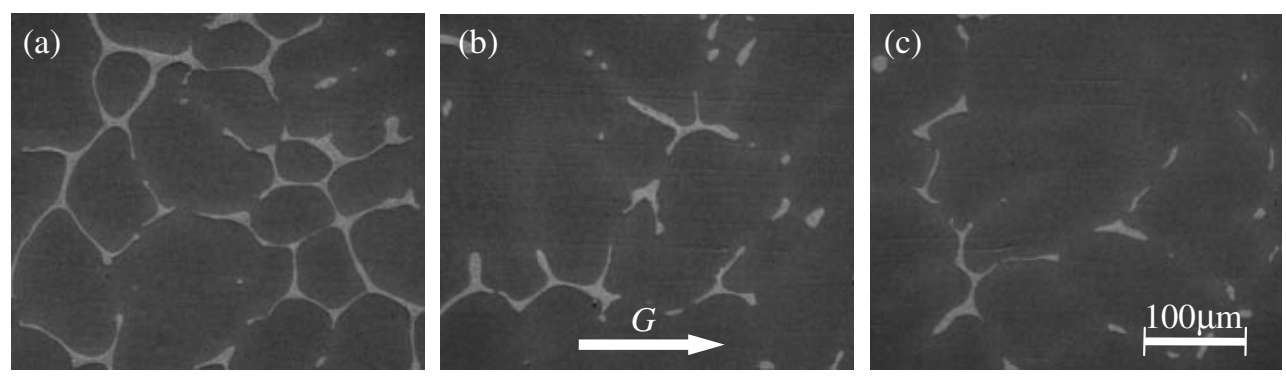

Fig. 5 The typical SEM microstructures of the $\mathrm{Al}_{-} \mathrm{Al}_{2} \mathrm{Cu}$ FGM ring. The arrow indicates the direction of the centrifugal force. (a) ring's inner region, (b) ring's interior region, (c) ring's outer region.

The effect of heat treatment on the hardness is also studied. To avoid the compositional gradient change due to the diffusion during the heat treatments, the fabricated FGM ring was cut into smaller samples. The smaller samples were encapsulated in an evacuated quartz tubes, and the heat treatments were carried out in a muffle furnace. The samples were heated at $550^{\circ} \mathrm{C}$ for $20 \mathrm{~h}$, and then quenched into water (solution treatment). Some of these solution treatment samples were aged at $160^{\circ} \mathrm{C}$ for $8 \mathrm{~h}$. X-ray diffraction (XRD) analysis was carried out for the samples before and after the heat treatments.

\section{Results}

\subsection{Microstructures}

Figure 5 shows the typical microstructures of the Al$\mathrm{Al}_{2} \mathrm{Cu}$ FGM ring fabricated from $\mathrm{Al}-3$ mass $\% \mathrm{Cu}$ alloy by the centrifugal in-situ method, where (a), (b) and (c) were taken at ring's inner, ring's interior and ring's outer regions, respectively. In this figure, an arrow indicates the direction of the centrifugal force. White phase is identified by EDX analysis to be the $\mathrm{Al}_{2} \mathrm{Cu}$ intermetallic compound and black regions are $\alpha-\mathrm{Al}$. White regions in these figures have a eutectic microstructure. Eutectic, which is formed in the final stage of solidification, is distributed in the grain boundary regions. The volume fraction of the eutectic can be evaluated using the Scheil equation, and that is $5.5 \%$, which is in a good agreement with experimental observations. It is found that the volume fraction of $\mathrm{Al}_{2} \mathrm{Cu}$ phase increases towards the ring's inner position (opposite the centrifugal force direction). This is because the $\alpha$-Al primary crystal particles migrate towards the outer periphery of the ring under the application of the centrifugal force, since the density of the $\alpha$ Al primary crystal is larger than that of the molten $\mathrm{Al}-\mathrm{Cu}$ alloy in the early stage of solidification. The volume fraction of $\mathrm{Al}_{2} \mathrm{Cu}$ intermetallic compound, therefore, increases towards the inner region of the ring.

In order to express the $\mathrm{Cu}$ concentration gradation in the $\alpha$ Al matrix quantitatively, the distribution of the $\mathrm{Cu}$ concentration in the FGM ring was measured by EDX analysis. Results are shown in Fig. 6, where the abscissa represents the position normalized by thickness of the ring; i.e. 0.0 is the inner surface and 1.0 is the outer surface. As it can be seen, the $\mathrm{Cu}$ concentration monotonically increases towards the ring's inner position. It was quantitatively confirmed that the $\mathrm{Cu}$ concentration increases towards the inner periphery of the ring.

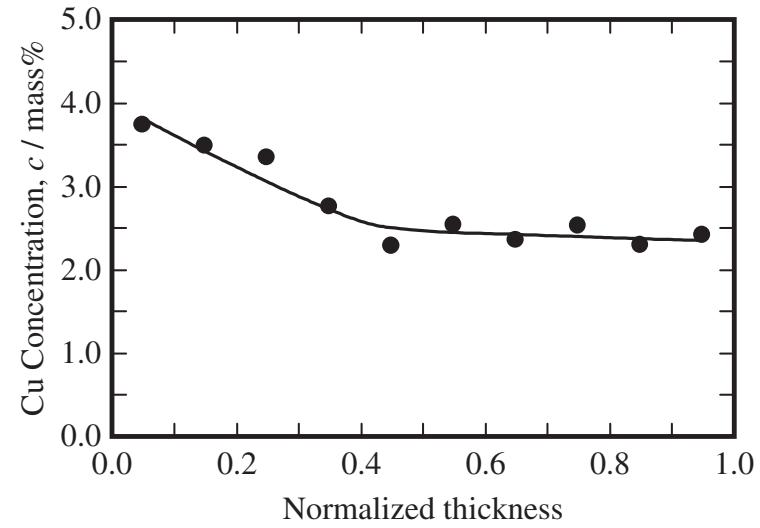

Fig. 6 Distribution of the $\mathrm{Cu}$ concentration in the $\mathrm{Al}^{-} \mathrm{Al}_{2} \mathrm{Cu}$ FGM ring measured by EDX analysis.

\subsection{Heat treatment}

Precipitation hardening is commonly employed with highstrength Al alloy. The mechanism of hardening has been studied most extensively for the Al-Cu alloys. Therefore, in this study, the smaller samples of fabricated FGM are heattreated. Although the figure is not presented here, it was found that the $\mathrm{Al}_{2} \mathrm{Cu}$ intermetallic compound could not be found after heat treatments (both solution treatment and aging). The $\mathrm{Al}_{2} \mathrm{Cu}$ will disappear by solution treatment and not form by precipitation during aging.

To discuss the above phenomenon, XRD analysis was carried out. Figures 7(a), (b) and (c) show the XRD patterns of sample, which is cut from an inner region of the FGM ring, before and after the solution treatment and aging, respectively. It is seen that the $\mathrm{Al}$ and the $\mathrm{Al}_{2} \mathrm{Cu}$ peaks co-exist before the heat treatments. Alternatively, the $\mathrm{Al}_{2} \mathrm{Cu}$ peaks disappear and only the $\mathrm{Al}$ peaks were found after the solution treatment. Moreover, the $\mathrm{Al}_{2} \mathrm{Cu}$ peaks cannot be detected after aging, since the heat treatment was carried out at low temperature for short time. Hence, the supersaturated solid solution and Guinier-Preston (GP) zones would be formed after the solution treatment and the aging, respectively.

\subsection{Density gradient}

Figure 8 shows the distributions of the density measured by Archimedes method and the theoretically calculated density. The theoretical density was calculated from $\mathrm{Cu}$ concentration in $\mathrm{Al}_{-} \mathrm{Al}_{2} \mathrm{Cu} \mathrm{FGM}$ ring shown in Fig. 6. As shown in Fig. 2, $\mathrm{Cu}$ solubility in $\alpha$-Al phase at $300^{\circ} \mathrm{C}$ is 0.68 mass $\% \mathrm{Cu}^{16)}$ On the other hand, Löchte et al. have 


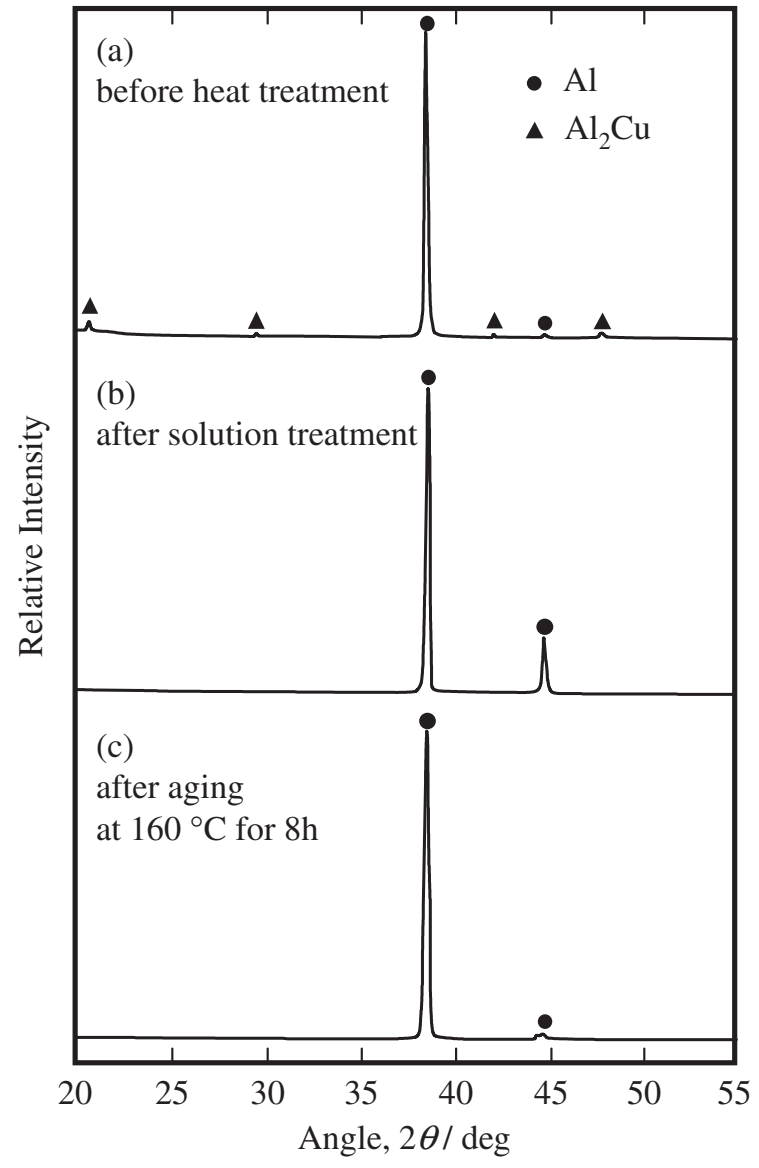

Fig. 7 XRD patterns of the FGM ring. (a): Before the heat treatments, (b): After the solution treatment and (c): After the aging at $160^{\circ} \mathrm{C}$ for $8 \mathrm{~h}$.

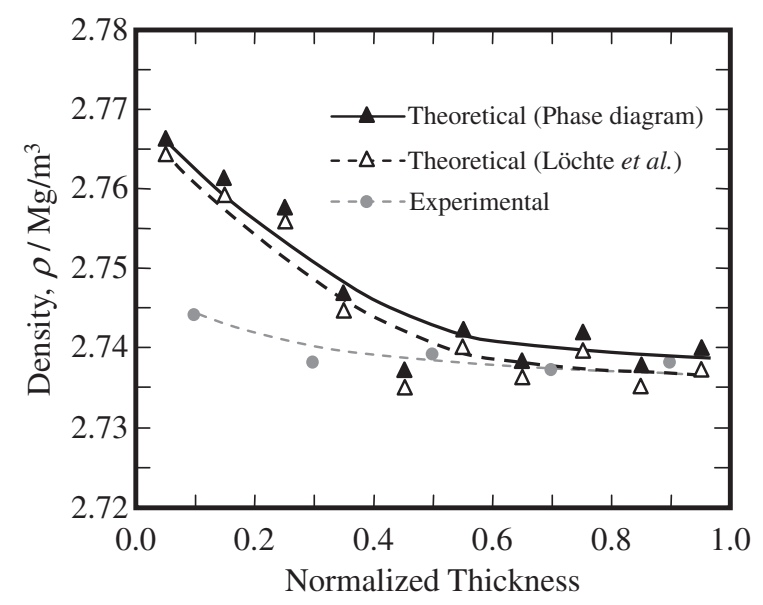

Fig. 8 Distributions of the measured and calculated densities in the Al$\mathrm{Al}_{2} \mathrm{Cu}$ FGM ring.

reported that $\mathrm{Cu}$ solubility below $200^{\circ} \mathrm{C}$ is less than 0.1 at. $\% \mathrm{Cu}(0.24$ mass $\% \mathrm{Cu}) .{ }^{19)}$ From these $\mathrm{Cu}$ solubility, $\mathrm{Cu}$ concentration used for the formation of $\mathrm{Al}_{2} \mathrm{Cu}$ phase at $300^{\circ} \mathrm{C}$ or below $200^{\circ} \mathrm{C}$ are 0.68 mass $\%$ or 0.24 mass $\%$ less than $\mathrm{Cu}$ composition shown in Fig. 6, respectively. Densities of $\mathrm{Al}-0.68$ mass $\% \mathrm{Cu}$ alloy and $\mathrm{Al}-0.24$ mass $\% \mathrm{Cu}$ alloy can be estimated as $2.706 \mathrm{Mg} / \mathrm{m}^{3}$ and $2.695 \mathrm{Mg} / \mathrm{m}^{3}$ from Fig. 1 , respectively. On the other hand, density of $\mathrm{Al}_{2} \mathrm{Cu}$ phase is

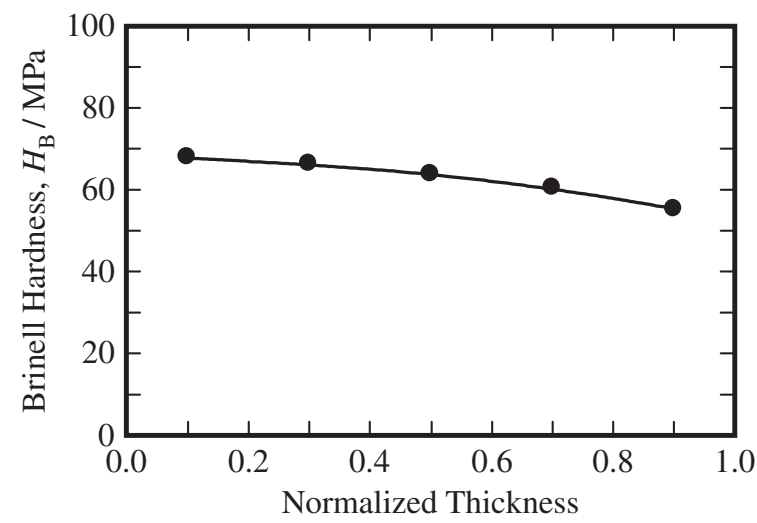

Fig. 9 Distribution of the Brinell hardness in the $\mathrm{Al}-\mathrm{Al}_{2} \mathrm{Cu}$ FGM ring before heat treatment.

$4.4 \mathrm{Mg} / \mathrm{m}^{3}$. Using these densities, volume fraction of $\mathrm{Al}_{2} \mathrm{Cu}$ phase can be obtained from the $\mathrm{Cu}$ concentration. The densities of $\mathrm{Al}-\mathrm{Cu}$ alloy calculated from the volume fraction of $\mathrm{Al}_{2} \mathrm{Cu}$ phase were plotted as theoretical densities in Fig. 8. Closed and open triangular plots show theoretical densities calculated using $\mathrm{Cu}$ solubility of 0.68 mass $\%$ at $300^{\circ} \mathrm{C}$ and 0.24 mass $\%$ below $200^{\circ} \mathrm{C}$, respectively. As can be seen from this figure, the density of $\mathrm{Al}-\mathrm{Al}_{2} \mathrm{Cu}$ FGM ring increases toward the inner region of the ring. In this way, the $\mathrm{Al}^{-\mathrm{Al}_{2} \mathrm{Cu}}$ FGM ring that has density gradient toward inner region can be successfully fabricated by the centrifugal method from dilute $\mathrm{Al}-\mathrm{Cu}$ alloy. As mentioned above, the volume fraction of $\mathrm{Al}_{2} \mathrm{Cu}$ intermetallic compound increases toward the ring's inner position. Therefore, the density increases toward the inner region of the ring, since the density of $\mathrm{Al}_{2} \mathrm{Cu}$ (4.4 $\left.\mathrm{Mg} / \mathrm{m}^{3}\right)$ is larger than that of pure $\mathrm{Al}\left(2.7 \mathrm{Mg} / \mathrm{m}^{3}\right)$. Also, the theoretical densities calculated from $\mathrm{Cu}$ concentration are good agreed with the density measured by Archimedean method.

\subsection{Hardness Gradients}

In order to study the gradient of the mechanical property, hardness tests were performed. It was shown that the Al$\mathrm{Al}_{2} \mathrm{Cu}$ FGM ring without heat treatment has dual-phase structure $\left(\mathrm{Al}\right.$ and $\mathrm{Al}_{2} \mathrm{Cu}$ ), and the coarser primary $\alpha-\mathrm{Al}$ and $\mathrm{Al} / \mathrm{Al}_{2} \mathrm{Cu}$ eutectic microstructure was found (Fig. 5). Therefore, measuring hardness by using a small indenter was not the best method to evaluate the hardness of the whole specimen. In the present study, the Brinell hardness test with a large indenter, whose diameter is $10 \mathrm{~mm}$, was adopted. In contrast, the FGM after heat treatments had quasimono-phase structure with the very fine microstructure. The micro Vickers hardness test was, therefore, carried out on the heat-treated specimens, since the detailed hardness distributions could be obtained.

The distribution of the Brinell hardness in the $\mathrm{Al}-\mathrm{Al}_{2} \mathrm{Cu}$ FGM ring before heat treatment is shown in Fig. 9. As it can be seen, the Brinell hardness of the ring's inner region is larger than that of the ring's outer region. This is because the content of $\mathrm{Al}_{2} \mathrm{Cu}$ intermetallic compound increases towards the ring's inner position, and the hardness of the $\mathrm{Al}_{2} \mathrm{Cu}$ intermetallic compound is much larger than that of the $\mathrm{Al}$. In this way, the $\mathrm{Al}-\mathrm{Al}_{2} \mathrm{Cu}$ FGM ring with hardness gradient can 


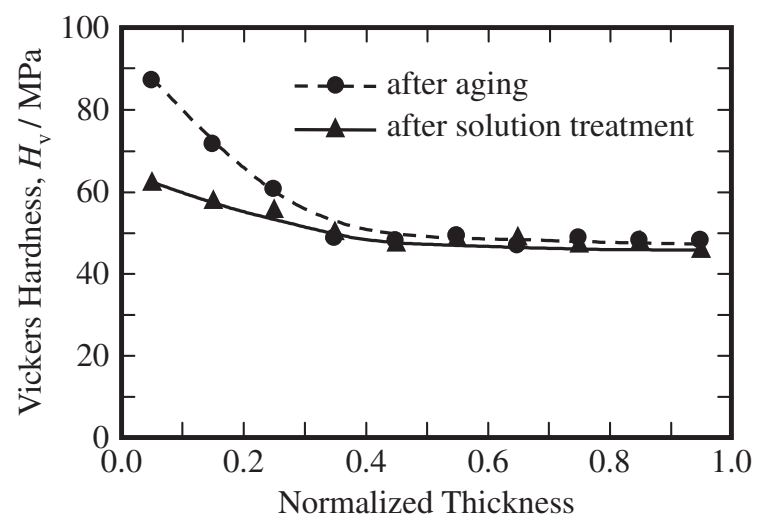

Fig. 10 Distributions of the micro Vickers hardness in the solution-treated specimen and in the aged specimen.

be successfully fabricated by the centrifugal in-situ method from dilute $\mathrm{Al}-\mathrm{Cu}$ alloy, when the hardness increases towards the inner region of the ring.

Figure 10 shows the distributions of the micro Vickers hardness after solution-treatment and aging. It is apparent that a higher micro Vickers hardness value was found around in the inner region of the ring. The micro Vickers hardness of the specimens at inner region of the ring increases in a large scale by aging. Although there is no evidence, GP zones should be formed by aging.

\section{Discussion}

In this study, it was found that the $\mathrm{Cu}$ concentration within the FGM ring monotonically increases towards the ring's inner position as shown in Fig. 6. This may come from the $\alpha$ $\mathrm{Al}$ particles migrate toward the outer region of the FGM ring under the centrifugal force, since the moving direction of the solid particles in the molten matrix could be determined by the density difference between the molten metal and particles. However, as shown in Fig. 4, the temperature dependence of the density for the solid phase is smaller than that for the liquid phase, and they are crossed at about $640^{\circ} \mathrm{C}$. Therefore, while the density of the primary $\alpha$-Al crystal is larger than that of a molten $\mathrm{Al}-\mathrm{Cu}$ alloy at a temperature above about $640^{\circ} \mathrm{C}$, the density of the primary $\alpha$-Al crystal is smaller than that of a molten Al-Cu alloy below about $640^{\circ} \mathrm{C}$. Since the primary $\alpha$-Al crystals migrate toward the outer region of the FGM ring below about $640^{\circ} \mathrm{C}$, non-monotonic gradation should be appeared within the fabricated FGM ring. This contradicts with the observed microstructure. In this section, we will discuss the formation of graded microstructure during the solidification under the centrifugal force.

During fabrication of the FGM ring by the centrifugal insitu method, the particles in the molten metal behave as a suspension of hard particles in a viscous liquid. Therefore, the composition gradient formed by the centrifugal in-situ method can be affected by the viscosity of the melt, as well as the difference in density between particles and a molten metal, the applied $G$ number, the particle size, the mean volume fraction of particles, and so on. During the solidification, the apparent viscosity of the melt (suspension)

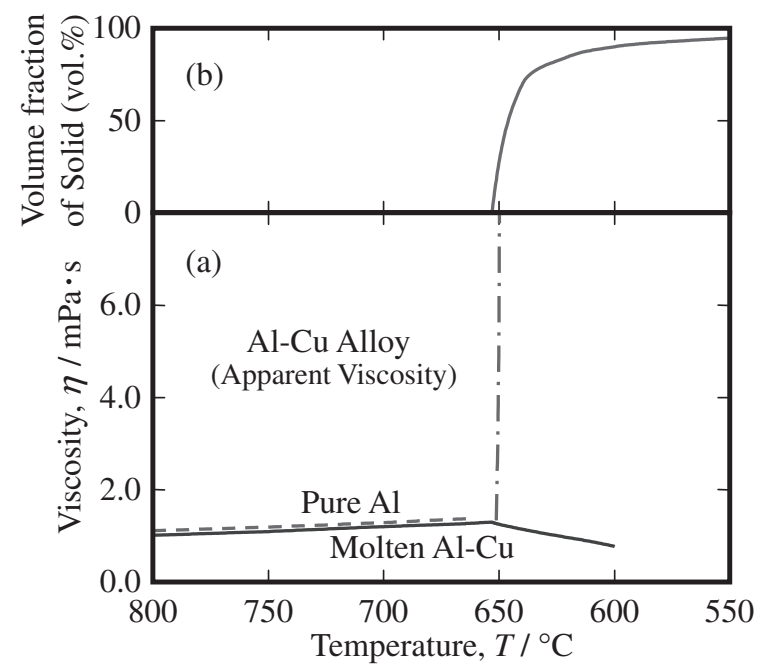

Fig. 11 (a) Temperature dependence of the viscosity and apparent viscosity for molten $\mathrm{Al}-\mathrm{Cu}$ alloy during the solidification of Al-3 mass $\% \mathrm{Cu}$ alloy, as well as that for pure Al. (b) Volume fraction of solid during the solidification of Al-3 mass \% Cu alloy.

should be influenced by the temperature, $\mathrm{Cu}$ concentration and volume fraction of solid.

It is known that the relationship between liquid viscosity $\eta$ (mPa.s) and temperature $T(\mathrm{~K})$ can be expressed by the Arrhenius' formula (Andrade's equation)

$$
\eta=\mathrm{A} \exp (B / R T)
$$

where $R$ is the gas constant $\left(=8.3144\left(\mathrm{~J} \cdot \mathrm{mol}^{-1} \cdot \mathrm{K}^{-1}\right)\right)$ and $A$ and $B$ are constants. ${ }^{20)}$ Measured and calculated values of $A$ and $B$ in eq. (5) for pure $\mathrm{Al}$ reported by Hirai are 0.2565 and $0.244(\mathrm{mPa} \cdot \mathrm{s})$ and 13.08 and $15.67\left(\mathrm{~kJ} \cdot \mathrm{mol}^{-1}\right)$, respectively. ${ }^{21)}$ Using these values, temperature dependence of the viscosity of pure $\mathrm{Al}$ can be calculated, and results are shown in Fig. 11(a).

The effect of $\mathrm{Cu}$ concentration on the viscosity of molten $\mathrm{Al}-\mathrm{Cu}$ alloy can be found in a literature. ${ }^{22)}$ There is a linear relationship between the $\mathrm{Cu}$ concentration and the viscosity when the alloy contains less than 20 mass $\% \mathrm{Cu}$. The viscosity of molten Al-20 mass \% Cu alloy is a half value of that for the pure $\mathrm{Al}^{22)}$ Therefore, the viscosity of molten $\mathrm{Al}-\mathrm{Cu}$ alloy during the solidification of $\mathrm{Al}-3$ mass $\% \mathrm{Cu}$ alloy can be evaluated, and results are also shown in Fig. 11(a). As can be seen, the viscosity increases slightly with decreasing the temperature before solidification starts, since the chemical composition of molten $\mathrm{Al}-\mathrm{Cu}$ is constant $(\mathrm{Al}-3$ mass\% $\mathrm{Cu}$ ). After solidification starts, in contrast, the viscosity decreases with decreasing the temperature, since the chemical composition of the molten $\mathrm{Al}-\mathrm{Cu}$ changes along the liquidus line, as shown in Fig. 2.

It is known that the viscosity of the melt increases according to the increase in number of particles in the suspension. Various equations have been proposed to predict the variation of the viscosity in the case of a relatively large volume fraction of particles. ${ }^{23)}$ Most useful is the Brinkmann equation, ${ }^{24)}$ which gives the apparent viscosity $\eta$ as

$$
\eta=\eta_{0} /\left(1-V / V_{\max }\right)^{2.5}
$$

where $\eta_{0}$ is the viscosity of the molten metal without 
particles, $V$ is the particle volume fraction and $V_{\max }$ is the maximum packing fraction. The $V_{\max }$ varies depending on the packing condition and the theoretical value is in the range of 0.52 for the simple cubic packing to 0.74 for the close packing of spherical particles.

To calculate the apparent viscosity of semi-solid alloy, the volume fraction of solid at each temperature is evaluated from Fig. 2 using the lever rule. Figure 11(b) shows the volume fraction of solid during the solidification of Al3 mass $\% \mathrm{Cu}$ alloy. Using this curve with eq. (6), apparent viscosity of $\mathrm{Al}-\mathrm{Cu}$ alloy during the solidification of $\mathrm{Al}-$ 3 mass $\% \mathrm{Cu}$ alloy is calculated, and results are also shown in Fig. 11(a). It is important to note that the apparent viscosity sharply increases with decreasing the temperature after solidification starts. The following equation was reported for the apparent viscosity of $\mathrm{Al}-10$ mass $\% \mathrm{Cu}$ semi-solid alloy. ${ }^{25)}$

$$
\eta=\eta_{0}\left\{1+\frac{2.41 \times 10^{6} C^{1 / 3} \dot{\gamma}^{-4 / 3}}{2\left(\frac{1}{f_{s}}-\frac{1}{0.72-8.82 C^{1 / 3} \dot{\gamma}^{-1 / 3}}\right)^{3}}\right\}
$$

where $f_{s}, C$ and $\dot{\gamma}$ are mass friction of solid, average solidification rate $\left(\mathrm{s}^{-1}\right)$ and shear rate $\left(\mathrm{s}^{-1}\right)$, respectively. The apparent viscosity rapidly increases when the fraction of solid is more than about 0.5 . This fact also supports our previous discussion.

Needless to say, the volume fraction of particles changes as the position on the ring changes. However, since the microstructural development during the centrifugal in-situ method is still not well understood, ${ }^{11)}$ the position dependency of viscosity will not be discussed any more. As shown in Fig. 4, the temperature $v s$ density curves for the solid and liquid phases are crossed at about $640^{\circ} \mathrm{C}$, and the density of the primary $\alpha$-Al crystal is smaller than that of a molten $\mathrm{Al}-$ $\mathrm{Cu}$ alloy below this temperature. However, at this temperature, since the volume fraction of particles is more than $70 \%$, the apparent viscosity is extremely high. Therefore, migration of $\alpha$-Al phase towards the innner periphery of the ring will not be occurred.

Thus, the formation of the graded composition in the FGM ring fabricated by the centrifugal in-situ method from Al3 mass $\% \mathrm{Cu}$ alloy could be summarized as follows. After the molten $\mathrm{Al}-\mathrm{Cu}$ alloy is poured into a rotating mold, the $\alpha-\mathrm{Al}$ primary crystals with 0.5 mass $\% \mathrm{Cu}$ are crystallized. Since the density of the $\alpha$-Al primary crystal (about $2.57 \mathrm{Mg} / \mathrm{m}^{3}$ ) is larger than that of the molten $\mathrm{Al}-\mathrm{Cu}$ alloy (about $2.46 \mathrm{Mg}$ / $\mathrm{m}^{3}$ ) at solidification temperature, the $\alpha$-Al primary crystal particles will migrate toward the outer periphery of the ring. During the solidification (cooling), the densities difference between the molten $\mathrm{Al}-\mathrm{Cu}$ alloy and $\alpha$-Al primary crystal particles becomes smaller and it becomes zero at $640^{\circ} \mathrm{C}$. However, at this time, volume fraction of solid is high enough, and the $\alpha$-Al primary crystal particles cannot migrate any more. Therefore, $\alpha$-Al primary crystal particles always migrate toward the outer periphery of the ring. Then, the remaining molten $\mathrm{Al}-\mathrm{Cu}$ alloy will solidify. At a eutectic temperature, $5.5 \%$ liquid phase with a eutectic composition will be retained, and the retained liquid phase may transform into the solid phases by the eutectic reaction. By this means, the volume fraction of the $\mathrm{Al}_{2} \mathrm{Cu}$ intermetallic compound increases toward the ring's inner position. The density should, therefore, increase toward the inner periphery of the ring, since the density of an $\mathrm{Al}_{2} \mathrm{Cu}$ intermetallic compound (the density is $4.4 \mathrm{Mg} / \mathrm{m}^{3}$ ) is larger than that of a pure $\mathrm{Al}$ (the density is $2.7 \mathrm{Mg} / \mathrm{m}^{3}$ ). Moreover, the hardness of the ring's inner position becomes larger than that of the outer region, since the hardness of $\mathrm{Al}_{2} \mathrm{Cu}$ intermetallic compound is larger than that of $\alpha$-Al.

\section{Conclusions}

In present study, the $\mathrm{Al}-\mathrm{Al}_{2} \mathrm{Cu}$ FGM ring with the density and hardness gradients was fabricated from $\mathrm{Al}-3$ mass $\% \mathrm{Cu}$ initial master alloy by the centrifugal in-situ method. Based on the present study, the following conclusions were made.

(1) It is found that the $\mathrm{Cu}$ concentration within the FGM ring monolithically increases towards the ring's inner position.

(2) The $\mathrm{Al}-\mathrm{Al}_{2} \mathrm{Cu}$ FGM ring, whose density increases toward inner region, can be successfully fabricated by the centrifugal in-situ method from dilute $\mathrm{Al}-\mathrm{Cu}$ alloy.

(3) It is found that the $\mathrm{Al}-\mathrm{Al}_{2} \mathrm{Cu}$ FGM ring with hardness gradient could be fabricated in which hardness increases towards the inner region of the ring.

(4) The hardness of the fabricated specimens at the inner region of the ring increases in a large scale by the heat treatments, since GP zones would be formed by aging.

\section{Acknowledgements}

The authors acknowledge the support of 21st Century COE Research by the Ministry of Education, Culture, Sports, Science and Technology of Japan and The Light Metal Educational Foundation Inc. of Japan for sponsoring the project. The authors also wish to thank Dr. Oleg Sitdikov for useful comments and suggestions on the manuscript.

\section{REFERENCES}

1) S. Suresh and A. Mortensen: Fundamentals of Functionally Graded Materials, Processing and Thermomechanical Behavior of Graded Metals and Metal-Ceramic Composites, (IOM Communications Ltd, London, 1998).

2) Y. Miyamoto, W. A. Kaysser, B. H. Rabin, A. Kawasaki and R. G. Ford (Eds.): Functionally Graded Materials: Design, Processing and Applications, (Kluwer Academic Publishers, Boston, 1999).

3) Y. Fukui: JSME Inst. J. Series III 34 (1991) 144-148.

4) Y. Watanabe, N. Yamanaka and Y. Fukui: Composites Part A 29A (1998) 595-601.

5) Y. Fukui and Y. Watanabe: Metal. Mater. Trans. A 27A (1996) 41454151.

6) Y. Watanabe, A. Kawamoto and K. Matsuda: Comp. Sci. Tech. 62 (2002) 881-888.

7) Z. M. Salim, N. Yamanaka, Y. Watanabe, Y. Fukui and S. Nunomura: ADVANCED MATERIALS AND PROCESSING" vol. 2, Proceedings of the 2nd Pacific Rim International Conference on Advanced Materals and Processing (PRICM-2), (The Korean Institute of Metals and Materials, 1995) pp. 1739-1744.

8) T. Ogawa, Y. Watanabe, H. Sato, I.-S. Kim and Y. Fukui: Composites Part A 37A (2006) 2194-2200.

9) Y. Fukui, K. Takashima and C. B. Ponton: J. Mater. Sci. 29 (1994) 2281-2288.

10) Y. Watanabe, R. Sato, K. Matsuda and Y. Fukui: Sci. Eng. Comp. 
Mater. 11 (2004) 185-199.

11) Y. Watanabe and S. Oike: Acta Mater. 53 (2005) 1631-1641.

12) Y. Watanabe, N. Yamanaka, Y. Oya-Seimiya and Y. Fukui: Z. Metallkd. 92 (2001) 53-57.

13) Y. Watanabe and T. Nakamura: Intermetallics 9 (2001) 33-43.

14) P. J. Way: Met. Trans. 5 (1974) 2602-2603.

15) K. Bornemann and F. Sauerwald: Z. Metallk. 14 (1922) 145-159.

16) T. B. Massalski (ed): Binary Alloy Phase Diagrams, (ASM International, Materials Park, 1988)

17) Japan Society of Thermophysical Properties (Ed): Thermophysical Properties Handbook, (Yokendo, Tokyo, 1990) p. 22. (in Japanese).

18) D. A. Porter and K. E. Easterling: Phase Transformations in Metals and Alloys, (Van Nostrand Reinhold Company, New York, 1981), p. 209.

19) L. Löchte, A. Gitt, G. Gottstein and I. Hurtado: Acta Mater. 48 (2000)
2969-2984.

20) R. F. Brooks, A. T. Dinsdale and P. N. Quested: Meas. Sci. Technol. 16 (2005) 354-362.

21) M. Hirai: ISIJ Inter. 33 (1993) 251-258.

22) F. D. Richardson: Physical Chemistry of Melts in Metallurgy, Volume 1, (Academic Press, London and New York, 1974) p. 26.

23) H. L. Frisch and R. Simha: The Viscosity of Colloidal Suspensions and Macromolecular Solutions, in "Rheology, Theory and Applications, vol. 1" ed. by F. R. Eirich, (Polytechnic Institute of Brooklyn, New York, 1956), p. 525.

24) H. C. Brinkman: J. Chem. Phys. 20 (1952) 571-571.

25) M. Hirai, K. Takebayashi, Y. Yoshikawa and R. Yamaguchi: ISIJ Inter. 33 (1993) 405-412. 